\title{
ESTRATEGIAS EDITORIALES DE LA PRENSA LITERARIA CATÓLICA EN EL SIGLO XIX CHILENO: LA ESTRELLA DE CHILE*
}

\author{
POR \\ EduARdo Aguayo ROdRÍGUEZ ${ }^{1}$ \\ Universidad Católica de la Santísima Concepción
}

\begin{abstract}
RESUMEN
El presente artículo busca contribuir a la historia de la prensa católica en Chile examinando las estrategias editoriales que sustentaron el trabajo de La Estrella de Chile (1867-1878), semanario literario vinculado a la prensa católica chilena. Para ello, identificaremos los lineamientos ideológicos, literarios y comerciales que intervinieron en la configuración del perfil particular de la revista, señalando las tendencias generales que permiten explicar su adscripción a la misión planteada por el periodismo católico de la época - defender la posición de la iglesia ante la secularización de la sociedad-y especificando las características particulares que diferenciaron su actividad en el marco de esta lucha.
\end{abstract}

PALABRAS CLAVE: prensa católica; siglo XIX; La Estrella de Chile; revista literaria.

\section{PUBLISHING STRATEGIES OF THE CATHOLIC LITERARY PRESS IN 19TH CENTURY CHILE: LA ESTRELLA DE CHILE}

\begin{abstract}
This article seeks to contribute to the history of the Catholic press in Chile by examining the editorial strategies that supported the work of La Estrella de Chile (1867-1878), a literary weekly linked to the Chilean Catholic press. In order to do this, we will identify the ideological, literary and commercial guidelines that configured the particular profile of the journal, pointing out the general tendencies that explain its ascription to the mission set forth by the Catholic journalism of the time - defend the position of the church in the face of the secularization of society - and defining the features that differentiated its activity within this process.
\end{abstract}

KEY WORDS: Catholic press; 19th century; La Estrella de Chile; literary magazine.

CÓMO CITAR ESTE ARTíCULO / CITATION: Aguayo Rodríguez, Eduardo. 2020. «Estrategias editoriales de la prensa literaria católica en el siglo XIX chileno: La Estrella de Chile». Hispania Sacra LXXII, 146: 569-578. https://doi.org/10.3989/hs.2020.042

Recibido/Received 20-03-2019

Aceptado/Accepted 10-10-2019

\section{INTRODUCCIÓN}

El estudio de la prensa periódica y especialmente de las revistas literarias y culturales en el ámbito del campo letrado

* Este artículo ha sido realizado en el marco del proyecto FONDECYT de Iniciación № 11170327, «(Re)presentando lo colonial: configuraciones narrativas y estrategias editoriales del tradicionismo chileno decimonónico».

1 eaguayo@ucsc.cl /

ORCID iD: https://orcid.org/0000-0002-7869-5821 chileno ha experimentado un sostenido avance por parte de la crítica especializada, adelanto que se articula con un proceso mayor, de alcance latinoamericano. Un indicador claro sobre este punto lo constituye la serie de proyectos de investigación financiados por la Comisión Nacional de Investigación Científica y Tecnológica, CONICYT, que abordan directa o indirectamente la revista como objeto de estudio, cubriendo un arco de intereses que abarca prácticamente la totalidad de la historia de la prensa periódica en Chile desde perspectivas críticas que, a pesar de privilegiar 
un acercamiento nacional, han integrado en los últimos años una mirada regional al tema. ${ }^{2}$ La producción académica derivada de estas investigaciones, vertida en ponencias, artículos y libros, ha sido prolífica, y permite bosquejar un panorama bastante comprensivo de este proceso; sin embargo, persiste el desconocimiento acerca de las particularidades que exhibe el desarrollo de este objeto cultural en el campo específico de la prensa confesional chilena, sobre todo en relación a su surgimiento durante el siglo XIX, fenómeno que ha sido estudiado fundamentalmente desde la perspectiva de la prensa doctrinaria (Bernedo 2006; Castillo, 2008; Cid 2012; Muñoz 2012). Frente a este vacío, el presente artículo se propone abordar el estudio de La Estrella de Chile, semanario literario católico que se destacó entre sus contemporáneos por haber logrado mantenerse en actividad por más de una década - lo que constituye sin duda una excepción en un medio caracterizado por la corta vida de sus publicaciones - a fin de indagar cuáles fueron las orientaciones programáticas que guiaron su actividad editorial y cómo estos lineamientos fueron interpretados por los distintos colaboradores que impulsaron este proyecto.

\footnotetext{
2 La lista comienza con «Proceso de legitimación discursiva de las revistas culturales y literarias chilenas (1842-1894)», proyecto FONDECYT N¹1110316 a cargo de la investigadora Marina Alvarado, quién además es responsable del proyecto FONDECYT 1170993 "Almanaques seculares chilenos (1850-1930): el origen desconocido del magazin en Chile», abordando en ambos estudios el funcionamiento de este objeto cultural en un periodo que va desde un momento fundacional del campo letrado nacional hasta su reconfiguración a partir de la integración de nuevos sujetos ciudadanos/lectores (Cfr. Subercaseaux 2002). Por su parte, Jaime Galgani, responsable de proyecto FONDECYT 11090054, "Literatura chilena y proyecto cultural en revistas de inicio del siglo XX (1900-1910)», analiza la presencia y validación de la literatura nacional así como la recepción de la literatura extranjera intersecular en las revistas culturales chilenas de principios del siglo XX, estudiando de paso el proceso de formación de la crítica literaria especializada que el desarrollo de este circuito editorial hizo posible. En una línea similar, Patricio Lizama investiga un corpus de veinte revistas artístico-culturales chilenas de la década del 1920 a fin de describir las características de la vanguardia artística y política articulada por y a través de estos medios, en el proyecto FONDECYT 1090735 "La vanguardia chilena en sus revistas (19201930): modernidad, poesía e intelectuales». Desde una perspectiva centrada en las prácticas materiales implicadas en la producción de la revista en tanto objeto, Claudia Darrigrandi desarrolla actualmente el proyecto FONDECYT 1190499 «Detrás de las secciones: trayectorias, saberes y oficios en revistas ilustradas/magazinescas y culturales chilenas (1900-1950)», investigación que se articula con el proyecto "Cultural intervention in Latin American magazines», financiado a través del programa de Apoyo a la Formación de Redes Internacionales de CONICYT, ampliando, de esta forma, el enfoque y alcance territorial de su propuesta. De manera similar, este enfoque material ampliado hacia un ámbito regional se verifica en el proyecto FONDECYT 1190182 «Revistas culturales latinoamericanas, recorte y globalización de la cultura en la primera mitad del siglo XX» de la académica Antonia Viu. Finalmente, César Zamorano enfrenta el objeto de estudio desde un acercamiento que integra las condiciones de desplazamiento y reterritorialización que afectaron el desarrollo del campo editorial tras la dictadura chilena en los proyectos FONDECYT 3150496, «Revistas culturales en Chile (1970-1990) y la conformación de un campo cultural», y FONDECYT 11170554 «Chile peregrino: revistas literarias y culturales en el exilio", este último en curso. Ambos proyectos han permitido la organización, en 2016 y 2018, de un Congreso Internacional sobre Revistas y Redes Culturales en América Latina, cuyo éxito refrenda la vitalidad de este campo de estudios a nivel regional.
}

Fundada en 1867, La Estrella de Chile $e^{3}$ fue un periódico "semanal, literario, relijioso i político ${ }^{4}$-como se autodefinió en la portada de los tomos que reúnen los primeros tres años de actividad-dirigido por el Consejo Directivo de la Sociedad de Amigos del País, de la cual dependía. La organización, fundada en 1865 por el destacado publicista católico Abdón Cifuentes, tuvo como objetivo principal coordinar el trabajo del mundo católico $-\mathrm{y}$ fundamentalmente de su juventud- en el ámbito público de las luchas políticas de la época (García 2004). Recordemos que la década del 1860 representó un punto de inflexión en la configuración del campo político nacional, que desde 1830 estuvo dominado por el bando conservador tras la victoria obtenida sobre los liberales en la Batalla de Lircay y la posterior elaboración de la Constitución de 1833, de carácter marcadamente autoritario. El continuo hostigamiento a la disidencia, que en 1851 causó una serie de motines y enfrentamientos armados a lo largo del país y, posteriormente, el estallido de la fallida Revolución de 1859, culminó a fines del gobierno de Montt con el quiebre de las fuerzas conservadoras y el apoyo de parte de estas a la candidatura del liberal José Joaquín Pérez, quien asumió la presidencia en 1861, dando inicio a tres décadas de gobiernos liberales. A partir de este momento, se verifica el ascenso del liberalismo como fuerza política y cultural hegemónica y la expansión del racionalismo, el positivismo y el evolucionismo como modelos explicativos del mundo entre la elite intelectual del país, proceso que significó, en términos muy simples, una merma en el poder detentado por la Iglesia Católica como garante del orden social tradicional, institución que perdió - con la laicización del matrimonio, la enseñanza y la administración de los cementerios - injerencia directa en asuntos de interés público, replegando parcialmente su dominio al ámbito privado de la familia.

Es importante destacar, por otra parte, que la posición central que ocupaba la Iglesia en la sociedad chilena venía siendo ya cuestionada por el poder político. En efecto, Ana María Stuven (2009) señala que a partir de la conformación de lo que Ilama república legal, el estado chileno buscó ampliar la base social de la nación bajo el concepto de la igualdad de derechos, lo que en la práctica significó la convergencia de nuevos actores sociales - fundamentalmente la burguesía y los emergentes sectores medios compuestos por artesanos y funcionarios públicos - en la conformación de un estado laico, con la consecuente disminución del poder de la Iglesia en el plano político, cultural y económico; este periodo, caracterizado por un progresivo anticlericalismo, comienza a manifestarse ya a partir de la década de 1840, y tuvo en la llamada Cuestión del sacristán (1851) un hito determinante que dividió el consenso de la elite sobre la relación política y administrativa entre iglesia y estado, pero que no afectó en profundidad la valoración que las clases dirigentes tenían del catolicismo en tanto que garante moral del orden público. ${ }^{5}$ Es recién a partir de 1870 , con la

\footnotetext{
3 En adelante $L E C$.

4 Hemos optamos por mantener la ortografía original de los textos citados.

5 Una excepción a este consenso de clase la plantea Francisco Bilbao en su texto Sociabilidad chilena (1844), opúsculo donde atacó duramente la influencia de la Iglesia en la vida civil de la nación y que le significó la acusación de herejía.
} 
emergente organización política de los sectores populares y el consecuente surgimiento de demandas sociales nacidas no de la tradición o la dirección estatal sino que de los intereses de los mismos grupos sociales concertados, que se tensiona el orden precedente, definido por la influencia transversal del catolicismo, para dar paso a una república integradora donde se profundiza la «gradual secularización de lo cotidiano» (León 2011, 483), proceso modernizador que se ve acompañado de una creciente preocupación por la «cuestión social» y el avance de las ideas socialistas entre el naciente proletariado nacional.

En el escenario descrito, ya desde la década de 1840 la Iglesia había actuado para contrarrestar el avance secularizador en el plano público a través de la gestación de una prensa de carácter fundamentalmente doctrinario, que se articuló como oposición a la prensa liberal representada por El Mercurio de Valparaíso y, posterior a 1855, por El Ferrocarril. La Revista Católica, semanario fundado en 1843, y El Estandarte Católico, diario que entró en actividad en 1874 , fueron los dos principales medios de prensa que la alta jerarquía eclesiástica empleó para hacer frente a los ataques de sus adversarios políticos en el debate público y fortalecer, de paso, la difusión de la doctrina católica entre el creciente público lector, amenazado por la influencia destructiva de una prensa que calificaban como «irreligiosa» (Poblete 2002; Bernedo 2006; Cid 2012; Cherniavsky 2015). En esta misma línea deberíamos situar la actividad del semanario La Estrella de Chile, que sin duda se plegó al objetivo general de la prensa católica, pero que al mismo tiempo configuraría una tendencia distintiva dentro de esta, ya que no solo se presentó ante el público como un colaborador en la lucha contra la prensa irreligiosa - como ocurre en el caso ejemplar de La Revista Católica - sino que desde un principio declaró entre sus objetivos promover el avance de las artes y la cultura nacionales desde el ideario católico, desarrollando un particular perfil mediático que la posicionó como una de las más longevas revistas culturales de la época, en un periodo en que, en promedio, la actividad de tales publicaciones no superaba el año de vida (Cornejo 2015).

En las líneas que siguen abordaremos el análisis de este perfil a partir del examen de las estrategias editoriales que orientaron su actividad. Entenderemos esta noción basándonos en la propuesta de Santa Cruz, que define las estrategias de un medio como un «conjunto de objetivos y definiciones políticas, periodísticas y empresariales que, combinadas entre sí, le dan un perfil propio [...], una identidad y una función en el escenario de las comunicaciones y una situación dentro del mercado de la información» (2010, 73). A partir de estos elementos, que Santa Cruz organiza en un modelo de tres dimensiones -ideológica/cultural, periodística y económica - a continuación proponemos analizar la conformación del perfil de este medio, enfocando la lectura en la descripción de tres componentes interrelacionados: la ideología del medio, referida a la posición doctrinaria sostenida fundamentalmente por antagonismo frente a lo que identificó como "prensa adversaria»; su textura informativa, que apunta a identificar los principios que regularon su producción textual, sobre todo en lo relacionado con la producción literaria, así como con los patrones de selección y exclusión ejercidos por el medio sobre esta materia de lectura, y, finalmente, el mercado lector que buscó articular, determinado en este caso por las decisiones discursivas y económicas que definieron un público lector específico, capaz de hacer viable el proyecto literario-doctrinal del medio.

\section{LA IDEOLOGÍA DEL MEDIO: POR UNA DEFENSA DEL CATOLICISMO EN LIBERTAD}

Situados en el plano ideológico, si bien tradicionalmente se ha considerado a $L E C$ como un órgano de la facción política conservadora, nos parece que tal afirmación merece ciertas precisiones. Sin duda, resulta evidente la posición de antagonismo que el medio adoptó en el campo periodísticoeditorial donde buscó situarse, dominado por la prensa afín al credo liberal. Previsiblemente, su entrada en este campo se expresó en términos de una retórica bélica: "A las ensangrentadas lizas de otro tiempo - señala el «Prospecto» con el que se presentó en su primer número-, han sucedido las columnas de los periódicos, a las lanzas las plumas: antes era necesario batirse; ahora es indispensable escribir» (Anónimo 1867). En este sentido, el llamado a publicar, es decir, a tomar las armas de la letra y entrar en «esta nueva arena de combate abierta a todos los principios i a todos los intereses" (ídem) se justificaba, en palabras del presbítero Servando Briseño, ante el avance de una prensa que, enfrascada en defender los intereses parciales de las distintas facciones políticas, desconocía «el objeto a que ha sido destinada por la Providencia [de dirigir] al pueblo por los senderos de la virtud i del progreso" (1867). Notemos que la noción de progreso que orientaba a los editores se oponía radicalmente a "esa triste gloria que el cinismo se ha encargado de bautizar con el nombre de progreso de las ideas: nosotros no la envidiamos ni siquiera la comprendemos» (Anónimo 1868, 1); es el progreso entendido en el sentido tradicional de evangelización civilizadora lo que les permitiría asumir una posición de contradicción y enfrentamiento respecto de lo que identificaron explícitamente como la prensa anti-católica, representada por diarios como El Ferrocarril, La Libertad y La Patria, todos animados, a juicio de los editores católicos, por un programa «hostil a las creencias, a las prácticas del culto i al sacerdocio de la relijión que profesa la mayoría de los chilenos» (R.B 1867, 111).

Sugerentemente, a partir de este "progreso en la fe», $L E C$ no tardó en asumir la defensa de la libertad como uno de sus propósitos declarados, construyendo una posición de resistencia -o como los mismos autores nombran en distintos momentos, de "reacción»- desde el mismo espacio retórico abierto por el ideario liberal progresista. Sabemos que, tras el proceso histórico que afectó al papado de Pío IX y que implicó la suspensión de su poder temporal y la pérdida de los Estados Pontificios, la Iglesia buscó combatir la expansión del liberalismo discursivamente, utilizando la rapidez y masividad que ofrecía la prensa para difundir una imagen de esta ideología como encarnación del mal (Muñoz, 2012). Esta posición, sin duda dominante dentro del campo letrado católico, coexistió, sin embargo, con una tendencia marginal, que buscó conciliar la fe religiosa con la defensa de la libertad, y cuyo exponente más notorio en el país fue el escritor, académico y publicista Zorobabel Rodríguez. De esta escuela de «liberalismo católico» (Correa 1997) participaba también el poeta y abogado Enrique del Solar, unos 
de los sostenedores más comprometidos con el proyecto editorial de $L E C$, como se puede inferir de la siguiente cita, extraída de su artículo "La reacción»:

Cada siglo tiene sus tendencias, cada jeneración ideas en cuyas aras se inmola. Luchar contra ellas, querer navegar contra la corriente, es perderse miserablemente. Las tendencias de nuestro siglo van hacia la libertad. Una reacción en su contra es absurdo inconcebible, i los llamados reaccionarios son los que más distantes se hallan de desear siquiera emprenderla $(1867,133)$

Tal planteamiento resulta sin duda llamativo, no solo por la perspectiva histórica que un católico ferviente como del Solar se permite para dar cuenta de la escenificación colectiva de su tiempo - inevitablemente lanzado hacia la libertad, como si se tratara casi de un determinante evolutivo que dirigiera el derrotero de su generación- sino también por el estratégico desprecio que exhibe ante la idea de una reacción contra esta suerte de ley natural, reacción que posteriormente atribuye a «los fariseos de la libertad [ ] que si la invocan es solo para ellos, negándola a los que como ellos no piensan ni pensarán jamás» (ídem), es decir, a los defensores no de la libertad en tanto que derecho, sino que del liberalismo en tanto que doctrina política. La defensa de la libertad resultaba, en efecto, imprescindible para sostener cualquier posición de contradicción respecto de las fuerzas políticas que alentaban el avance secularizador, en la medida en que la instalación hegemónica del liberalismo era interpretada como contradictoria al ejercicio mismo de la libertad, contradicción que del Solar subrayaba explícitamente al insistir que, paradojalmente, «al pensamiento católico se le niega el campo en nombre de la libertad» (ídem). Esta ideafuerza señalará parte del fundamento ideológico del periódico durante su etapa abiertamente política; sin embargo, la publicación fue revertiendo esta actitud conforme consolidó su actividad en el tiempo.

En efecto, si ya en su primer prospecto los editores declaraban que «la política nos interesa a todos por lo mismo que se roza con todo» (Anónimo 1867) y profundizaban esta visión en el recuento de su primer año de actividades, donde destacaban que «en la polémica política no hemos tenido otro norte que servir leal i francamente los intereses de la libertad i los intereses de la justicia» (Anónimo $1868,1)$, a partir de su cuarto año de existencia, la revista comenzó a moderar su carácter político, pasando de ser "en política, [ ] espectadora, observadora, no combatiente» (Anónimo 1870d, 1), a actuar en política solo si «el movimiento político compromete algún principio, algún interés relijioso, [ ] poniéndose en todo caso del lado de la verdad, de la justicia i de la relijion» (ibíd., 2) -y notemos que ya no de la libertad- para terminar «apartados de la política, de esa política ardiente que riñe, de esa política de bandos, de hombres, del día presente» (Anónimo 1873a), ya que "los colaboradores de La Estrella de Chile no reconocen otra bandera que la de su fe relijiosa i de la justicia. La Estrella de Chile no sirve a la política» (ibíd., 2). Este cambio de actitud puede vincularse con la percepción de que una participación activa en la lucha política contingente amenazaba, en cierta forma, la defensa de los intereses de la Iglesia en el terreno público, en la medida en que se constituía como potencial factor de división interna. Al respecto, es interesante destacar la crítica que tempranamente se deslizó contra quienes «sacrifican el interés de la relijión que profesan en aras de las mezquinas conveniencias del partido a que sirven [y] son antes que católicos, hombres de partido» (R.B.1867, 112). Si bien el articulista identificaba explícitamente como el objeto de su crítica a los miembros del llamado «monttvarismo» -es decir, la vertiente laica del espectro político conservador, por esas fechas en alianza con los radicales y en oposición al clericalismo ultramontano-, era el apasionamiento político que movía a la gran masa de los lectores católicos a consumir las noticias propagadas desde la prensa «anticatólica», con el consecuente sostenimiento económico de su actividad productiva, lo que a su juicio constituía la amenaza más grave y directa para la expansión editorial de la Iglesia, como veremos más adelante. ${ }^{6}$

Más importante aún, la distancia estratégica que progresivamente fue adoptando la dirección de $\angle E C$ respecto de la política contingente acompañó un proceso inverso, de creciente interés por posicionar su lucha contra el avance secularizador del liberalismo en el terreno abierto por el debate cultural. En este sentido, recordemos que la rápida transformación del campo periodístico chileno durante la década de 1870 significó la consolidación de una prensa esencialmente diversificada, orientada a satisfacer las expectativas de un público nuevo, «un público ya con características de moderno, en el sentido de una demanda orientada a las funciones luego consideradas clásicas de los medios masivos modernos: informar, educar u orientar, $y$, en especial, entretener» (Ossandón 1998, 56), lo que trajo consigo una progresiva marginación de la prensa doctrinaria "o de ideas», dominante durante la primera mitad del siglo XIX. Esta nueva configuración de las demandas lectoras, que sin duda fue interpretada como una condición que determinaría el curso de la cultura letrada en el país, pareció justificar la declaración de principios sostenida por Rafael B. Gumucio, director del semanario a partir de 1870, al afirmar que $L E C$ «no está encargada de la lucha palpitante del día; su tarea es abrir pacientemente el surco e ir derramando en él la semilla del bien, puñado a puñado; la obra de $L a$ Estrella de Chile es obra del porvenir» $(1877,81)$. Este germen dispensado hacia el futuro no era otro que la semilla de «las bellas letras, la literatura lijera, las obras de fantasía» (ibíd., 78), necesarias también para «los espíritus de un país civilizado» (ídem). Esta última observación nos permite avanzar en nuestro análisis para abordar el estudio de los lineamientos que orientaron el proyecto literario de $L E C$, a la luz de la definición de una cultura nacional en proceso de transformación.

LA TEXTURA INFORMATIVA: POR UNA VEROSIMILITUD NO REALISTA PARA LA LITERATURA NACIONAL

En el mismo «Prospecto» con que inauguraron su publicación, la dirección de $L E C$ declaraba el propósito principal del semanario en los siguientes términos:

6 Esta tesis coincide con un aspecto central tratado en el folleto Los periódicos irreligiosos ante la conciencia católica. Actitud de los católicos frente a la mala prensa (1868), redactado por el presbítero e historiador Crescente Errázuriz, texto que articuló la postura de la Iglesia chilena contra la amenaza que constituía la circulación de una prensa irreligiosa (Cfr. Cherniavsky 2015, 119,120). 
Queremos con nuestros ensayos literarios, contribuir, aunque sea en la más modesta escala, al cultivo de la intelijencia i al incremento de la ilustración en el país; fomentar la veneración por la verdad i el gusto por lo bello; atacar de alguna manera a los vicios i prestar cualquier apoyo a las virtudes; en una palabra, ensalzar i enaltecer, tanto como ellos merecen, los intereses morales de la humanidad, a las veces tan deprimidos, pospuestos i sojuzgados por el tumulto i ruido de los intereses materiales (Anónimo 1867).

La afirmación inaugural, planteada en una terminología más afín al universalismo clásico por su visión humanista e ilustrada que a un proyecto literario de raigambre nacional, alineaba a $L E C$ en una tendencia generalmente compartida con el resto de los medios de prensa católicos del momento, que vio en la literatura en general y en la novela-folletín en particular una amenaza a la moral pública, entendida como el amplio repertorio de costumbres tradicionalmente sancionadas por la norma religiosa (Cherniavsky, 2015). En este sentido, es posible reconocer entre los colaboradores de LEC una postura crítica e incluso defensiva respecto del cultivo de la literatura, especialmente en su vertiente romántico-masiva, donde convergen Byron, Goethe, y Víctor Hugo pero también Eugenio Sue y Ann Radcliffe. Se trataría de obras que, lejos del ideal horaciano de «ilustrar deleitando» al cual se plegaron tempranamente los directores de $L E C$, solo cumplirían la función de «iniciar al lector en el complicado juego de los sentimientos reprensibles del alma, por el arte de soltar la rienda a los malos instintos i de regalar al público con escenas vergonzosas» (Sánchez 1873, 75). Notemos, sin embargo, que la nocividad de esta influencia espiritual fue interpretada también en términos de su inadecuación respecto de un cuerpo nacional imaginado/ deseado, en la medida en que las "enfermizas creaciones de los discípulos de Byron o Goethe [resultaban] indignas de un pueblo joven, robusto y creyente, como el pueblo chileno» (Anónimo 1868, 1). Acorde a esta concepción de la nación como un recién nacido «que apenas asoma su jentil cabeza sobre el horizonte de la vida", los colaboradores de LEC se propusieron desarrollar una voz literaria que fuese capaz de expresar la potencia auroral de un orden al que reconocían como "nuevo», en contraste con el decadente e incluso depravado estro europeo, ese «lánguido canto con que los eunucos del serrallo arrullan el sueño voluptuoso de un señor enfermizo i raquítico» (ídem). ${ }^{7}$

De esta forma, una de las primeras medidas adoptadas por la dirección de $L E C$ fue el establecimiento, a partir de su tercer año de existencia, de una serie de certámenes que tuvieron por objetivo estimular la producción literaria entre sus jóvenes lectores y, de paso, incidir en la consolidación de un incipiente mercado literario, punto que examinaremos en el último apartado de este estudio. Vale la pena registrar algunos hitos que marcaron la historia de estos concursos. La convocatoria al primer certamen -cuyo premio consistía en un monto de cincuenta pesos y la publicación del texto en las páginas de $L E C$ - estuvo pobremente definida, y, salvo por una acotación marginal — «Cada cuento llevará

Esta actitud de abierto rechazo marcó la tónica durante toda su vida editorial; sin embargo, también mostró fisuras, como puede verse en los poemas dedicados al mismo Byron e incluso en algunas traducciones de sus versos que $L E C$ publicó en ocasiones. al pie un seudónimo o iniciales»- (Anónimo 1870b), no entregó mayores precisiones sobre el género, la dimensión, el contenido o la intención de las obras a participar, aunque sí informó a los participantes que las obras serían evaluadas por Zorobabel Rodríguez, Enrique del Solar y Carlos Walker Martínez, figuras ya reconocidas dentro del circuito literario católico de la época. Los jueces declararon ganadora la novela moral El vértigo de un Vicio, de Valentín Murillo, obteniendo una mención honrosa el joven Máximo Lira por A orillas del Biobío, de temática indianista. En agosto de 1870 se convocó un segundo certamen, esta vez para otorgar «un premio de 100 pesos al autor del mejor cuento en prosa» (Anónimo 1870c), definido por un jurado compuesto por Miguel Luis Amunátegui, Domingo Arteaga Alemparte y Camilo Cobo, figuras principales del bando liberal. Este segundo concurso fracasó, según declararon los organizadores, debido a que los jueces no emitieron su dictamen «a causa del recargo de trabajo que, en su calidad de diputados, tuvieron a fines del año pasado» (Anónimo 1871b). A pesar de este contratiempo, al comenzar su séptimo año de circulación se organizó un tercer certamen, esta vez para premiar «una novela inédita orijinal de mediana estensión, ajustada a la moral católica» (Anónimo 1873b, 3), quedando designados designándose como a jueces Abdón Cifuentes, José Tocornal y el poeta José Antonio Soffia, y resultando ganador el poeta y colaborador del semanario Enrique del Solar con La peña de los enamorados, basada en una leyenda española que narra una historia de amor trágico entre una musulmana y un cristiano.

En el contexto de estos certámenes periódicos, Zorobabel Rodríguez desarrolló una serie de artículos que, vistos en perspectiva, delinearon una propuesta literaria orientada a guiar la producción futura de los jóvenes letrados católicos, y que puso énfasis en los aspectos técnicos de su escritura, dimensión que había estado mayormente ausente en las consideraciones anteriores. En este ámbito, es muy interesante considerar lo que Rodríguez denominó los «escollos» de la novela, en los que frecuentemente naufragaban los nóveles colaboradores del periódico: falta de sobriedad en el estilo, preferencia por el idilio como modelo narrativo, exceso retórico de las declaraciones románticas y recepción acrítica de lo que llamó «el falso americanismo literario». Examinemos brevemente lo expuesto en este verdadero programa narrativo.

En lo concerniente al lenguaje literario, la propuesta de Rodríguez apuntó a promover la austeridad formal, en afinidad con la función ilustrada que dominó el programa general de $L E C$ : toda palabra debía estar subordinada a la expresión de una idea, a un pensamiento, por lo que quien se iniciaba en el arte de narrar debía, para Rodríguez, «limitarse a espresar sus ideas con claridad i corrección. Nada de figuras, de amaneramiento; sobriedad en las palabras, sencillez en el estilo, naturalidad en todo» (1870a, 742). Esta lengua desnuda era la más apropiada para aquellas obras que buscaban resistir la seducción ejercida por la artificialidad del idilio, modelo que no solamente atentaba contra la verosimilitud de lo narrado, sino que también impedía el desarrollo de los elementos dramáticos que constituirían la "verdad» de la novela moderna. Si, por una parte, la trampa de situar la acción artificialmente en el escenario del idilio hacía «que los patanes discurran como pudieran 
los más aventajados injenios i [transforma] en románticas damas a campesinas ignorantes i toscas» (ibíd., 743), por la otra impedía al novelista abordar el campo propio de la narrativa:

Es en el bullicio de las ciudades, en el choque continuo de las pasiones i de los intereses, en la diversidad de situaciones i de caracteres, en el contraste que ofrecen la opulencia de unos i la miseria de otros, la virtud de estos i la maldad de aquellos, donde está el campo propio, fecundo, inagotable, reservado al novelista de talento (Ídem).

Vinculado a estos dos primeros puntos, el exceso romántico contravenía, a juicio de Rodríguez, las máximas de sobriedad y credibilidad declaradas al principio, y al mismo tiempo introducía un potencial de distorsión en relación al horizonte moral del texto literario, potencial que sin embargo se aceptaba como un riesgo necesario de asumir. En este sentido, para el autor «la pasión en la Novela suele ser lo principal» (ídem); sin embargo, para ser efectiva en el plano literario tenía que construirse de forma verosímil: «es preciso que el lector en vez de oírla charlar la vea moverse. Es preciso que el que lee, viendo como obran los amantes, esclame involuntariamente: ¡Cómo se aman!, no que ellos mismo, bajo la fe de su palabra, se encarguen de repetirlo en cada capítulo» (ibíd., 744); de igual forma, para ser moralmente aceptable, esta pasión romántica debía conducirse dentro de los límites de la virtud, so pena de caer «en el precipicio de lo ridículo, de lo inmoral, de lo provocativo, de lo indecente i hasta de lo asqueroso" (ídem).

Finalmente, en relación a la idea de un "falso americanismo", Rodríguez parece haberse hecho cargo de la preocupación de sus contemporáneos por consolidar una novelística nacional entendida como expresión cultural de la autonomía política obtenida tras las guerras Guerras de Independencia, anhelo fundacional inaugurado, en Chile, con la generación literaria de 1840 . Consciente de este proyecto de larga data, Rodríguez interpretó el desarrollo de la novela de temática indígena - que en efecto tuvo una importante aceptación entre los colaboradores de LECcomo una consecuencia negativa derivada de la legítima preocupación por «americanizar» la literatura, interés que, mal entendido, terminaría por «barbarizarla». El defecto que Rodríguez atribuyó a esta novelística no se limitaba al problema de la verosimilitud, aun cuando insista en esgrimir la máxima de veracidad como principal argumento - punto en el cual vuelve Amado Láscar (2005a) al dar cuenta sumaria de la novela indianista desarrollada por los jóvenes autores católicos asociados a $L E C$ - , sino que implicaba un error de concepto en relación a lo que las jóvenes repúblicas debían entender como "lo propio americano», por oposición a un orden moral, cultural e incluso temporal que era comprendido bajo el signo de la alteridad absoluta. En palabras del propio Rodríguez:

No es entre las pobres tribus de bárbaros que pueblan todavía algunas comarcas de nuestro continente, como un turbio lago próximo ya a secarse, donde pueden encontrarse tipos del verdadero americano, i donde pueden estudiarse las ideas, las tendencias i los elementos todos de la sociedad en que vivimos, dueña del presente i señora también del porvenir (1870b, 755).
Pese a esta advertencia, y si bien las colaboraciones literarias publicadas por $L E C$ se ciñeron en general a las disposiciones elaboradas por Rodríguez, es importante destacar la propuesta literaria de un grupo de jóvenes escritores que, tomando distancia de este ideal estético, buscaron en las crónicas coloniales los modelos y los temas con los que delinearían una particular expresión novelesca del pasado nacional. En efecto, "Gualda, leyenda indiana» (1867) y «A orillas del río Bío-Bío, escenas de la vida araucana» (1870) de Máximo Lira; "Cailloma» (1870), de Raimundo Larraín; "Guacolda, Leyenda araucana» (1872) de David Bari y, a partir de 1874, las tradiciones y «leyendas nacionales» de Enrique del Solar integraron en sus tramas narrativas una visión fraterna del mundo, herencia hispánica legada por Bartolomé de las Casas, Francisco Núñez de Pineda y Bascuñán y el padre Luis de Valdivia, junto al imaginario crítico fundado por Ercilla en La Araucana, para dar forma a una síntesis narrativa en donde la coexistencia de lo español, lo criollo y lo indígena era posible dentro de los límites de una deseada nación cristiana (Cfr. Láscar 2005b; Barraza 2013).

Por otra parte, y a partir de la definición de los límites negativos que conformaron esta preceptiva narrativa, Rodríguez pasó a señalar las dos condiciones esenciales que deberían normar los trabajos literarios de los nóveles escritores-colaboradores de LEC. La primera consistía en privilegiar la configuración de la trama narrativa, lo que el crítico llamó el «interés dramático» de la novela, por sobre las consideraciones didácticas que inevitablemente intervenían en el programa moral e ilustrado del semanario católico pero que fueron, hasta cierto punto, relativizadas por esta premisa: «hai tantos hombres apreciables - subraya Rodríguez - que pierden su tiempo i su talento escribiendo lecciones de moral en forma de novelas, lecciones que no tienen sino el inconveniente de no ser leídas por nadie» (1870b, 758). Este componente dramático fue explicado en términos de un conflicto estructurante a partir del cual se debía desplegar narrativamente la visión de mundo promovida por la posición doctrinaria del semanario, descrita en el apartado anterior: «Donde no haya lucha entre la virtud i la materia, entre lo ideal i lo real, entre la inocencia i el crimen, no existe la materia prima de una novela» (ibíd., 757). La segunda condición insistía en la idea de enmarcar este conflicto en un escenario verosímil, lo que implicaba construir descripciones exactas y sobre todo (re)conocibles, reforzando la idea de una literatura culturalmente identificada e incluso territorialmente situada: "el novelista no debe describir nada que no esté en situación de describir con verdad i [...] no debe llevar a sus lectores a ningún sitio cuyo color local no haya percibido con sus propios ojos» (ibíd., 759). Esta máxima de verosimilitud debía encarnarse, finalmente, en caracteres densamente particularizados, delineados a partir de una "fisonomía moral [...] que constituye la personalidad de un individuo, ese algo, vicio o virtud, defecto o perfección, que en el alma como en el cuerpo de cada hombre es como el distintivo i el sello de suyo" (ídem).

A pesar de estas consideraciones técnicas que enfatizaron la verosimilitud como valor cardinal del proyecto literario católico, hay que destacar, sin embargo, que operó en el planteamiento del crítico un explícito rechazo al realismo, entendido como una corriente literaria que proclamaba «la fotografía por procedimiento y la perfección de la forma 
por ideal» (Rodríguez 1871b, 33), sacrificando en este gesto lo que para él constituía la esencia misma del arte: la creación de la belleza por expresión sensible de lo ideal. Este fundamento filosófico, si bien parece remitir en último término a los postulados estéticos del idealismo hegeliano, probablemente fue desarrollado por influencia directa de los sermones del jesuita francés Celestino José Felix (1866), a su vez divulgador de las enseñanzas filosóficas de Víctor Cousin, para quien «La verdadera belleza es la belleza ideal, i la belleza ideal no es más que un reflejo de lo infinito» (Cousin 1873, 199). Sin intentar profundizar en los alcances filosóficos de este punto, tarea que excede las ambiciones de este estudio, nos parece que este tráfico de lecturas permite entender ciertas posiciones ambivalentes adoptadas por Rodríguez respecto del «ideal literario» al que debían aspirar los escritores de LEC: si la ambición de dotar a la obra literaria de «un alma espiritual que le impida caer en el charco del sensualismo, i un cuerpo que le impida evaporarse entre las nubes» (Rodríguez 1871b, 34) acercó la visión del crítico al arte clásico, entendido en términos hegelianos como la adecuación entre forma material y contenido ideal, predominó en su discurso una conciencia de raíz romántica que reconocía el exceso inaprensible del sentimiento - en tanto que superación de la finitud material moderna- en relación al limitado poder del poeta, situación de desbordamiento que le permitió hacerse eco de las palabras de Lamartine, al declarar que "entre lo que se siente i lo que se espresa hai la misma diferencia que entre el alma humana i las veinticuatro letras del alfabeto» (Rodríguez 1871a, 19).

\section{EL MERCADO LECTOR: DEFINICIONES ECONÓMICAS PARA UNA FIDELIZACIÓN DE LA LECTURA}

Por otra parte, esta serie de definiciones doctrinales y literarias debieron enfrentarse al desafío de lograr la sustentabilidad económica del proyecto en un mercado lector percibido como reducido en dimensión y poco inclinado a la lectura, condición estructural que ha representado un problema de larga data para el campo editorial chileno, como ha detallado Juan Poblete (2005) en su estudio sobre la consolidación de los públicos lectores desde mediados del siglo XIX y lo refrendan las actuales políticas públicas enfocadas en el fomento lector (CNCA 2015). En este sentido, junto con su propósito de incentivar la producción literaria entre la juventud católica y proporcionar «una lectura fácil, amena i moral para las familias» (Anónimo, 1870d, 1), los editores de $L E C$ comprendieron que para hacer viable a largo plazo la defensa de los intereses católicos por medio de un proyecto literario de carácter nacional resultaba necesario colaborar con el esfuerzo mayor, asumido junto a otras revistas literarias de la época, por «romper el hielo de la jeneral apatía, i [..] crear un público para las producciones literarias» en el país $(1872,450)$. La importancia que dio la dirección de $L E C$ a este asunto se trasluce en los artículos y editoriales que abordan esta situación, no sin cierta ironía: «Suscribase Ud. a nuestro diario, a nuestro periódico, a la revista que dirijimos, es la frase obligada con que se saluda al que se acerca, de buena o mala gana, al infeliz a quien el diablo mete en la cabeza la tentación maldita de hacerse hombre de letras» declaraba Ventura Blanco en «¿Se lee o no se lee» (1872,
485-486). El mismo artículo repasaba las causas más frecuentes que se esgrimían para explicar la corta vida alcanzada por la mayoría de los periódicos durante la época: falta de lectores, pobre calidad literaria de lo publicado, escaso o nulo apoyo económico a los colaboradores, preferencia por las lecturas importadas desde Europa, entre otras; sin embargo, el texto cerraba con una prueba irrefutable, a juicio del autor, de que el país contaba con un mercado lector suficiente para mantener la publicación de una revista literaria nacional: "Se Ilama La Estrella de Chile i llega al fin del quinto año de su publicación. iLuego, en Chile se lee!» (ibíd., 487). En este último apartado se busca examinar las decisiones editoriales que posibilitaron el éxito de $L E C$ en este precario mercado lector.

En relación a uno de los aspectos económicos más concretos que definen la estrategia de mercado de un medio - su valor de cambio-, las condiciones de suscripción declaradas en el primer número de LEC fijaban un pago anticipado de 10 pesos por un año de revista, 5.50 pesos para un semestre de suscripción, 3 pesos para suscripciones semestrales y 25 centavos de peso para el número suelto; sin embargo, estas tarifas fueron rebajadas a partir de su sexto número, quedando establecido un nuevo valor de 6 pesos para un año de suscripción, 3.50 pesos para la suscripción semestral y 2 pesos para un trimestre de revista, manteniéndose el valor de 25 centavos para números sueltos. Este rápido cambio significaba adecuarse a una estructura de precios más acorde al mercado, si tomamos como referencia los precios de suscripción de La Semana, revista de literatura, ciencias, noticias y modas contemporánea a LEC y dirigida por Julio Chaigneau en Valparaíso, que definía un pago de 5 pesos de pago adelantado por un año, y de 3 pesos por semestre. Este valor se mantuvo hasta el octavo año, cuando LEC modificó sustancialmente su formato, pasando de 32 páginas a 40 páginas en cuarto, aumentando un $25 \%$ en material de lectura, lo que provocó un incremento en el valor de su suscripción, que a partir del 11 octubre de 1874 volvió a los 10 pesos por pago anual dentro del país, y doce pesos anuales, para las suscripciones en el extranjero.

A pesar de no contar con datos concretos acerca del tiraje de la publicación - cuyo número solo se califica de «copioso»-, el hecho de que a partir de su tercer año de publicación fuera frecuente encontrar avisos donde la dirección ofertaba la compra de colecciones completas de los primeros dos años de la revista, grafica la positiva recepción que tuvo entre el público lector, que no solo agotó los ejemplares disponibles sino que sostuvo la demanda en el tiempo, al punto de que, entrado el cuarto año de publicación, las ofertas por una colección completa de $L E C$ alcanzaban los 30 pesos (Anónimo 1871c). Del mismo modo, existen indicios que permiten suponer una importante cantidad de suscripciones mantenidas desde el extranjero. Sobre este punto, en el «Prospecto» que inaugura el octavo año de la revista, los editores de $L E C$ informaban:

En virtud de haber crecido tanto el número de nuestros suscritores de fuera de Chile i a petición de algunos de éstos, recibirán cada quince días, junto con $L a$ Estrella de Chile, una hoja por separado que contendrá noticias literarias, comerciales i políticas de lo ocurrido en Chile durante la quincena (Anónimo 1874a, 4). 
La circulación que logró LEC entre los lectores del continente debió hacer sido considerable, como lo demuestra la carta remitida al editor por el destacado humanista colombiano Rufino José Cuervo, requiriendo información sobre el uso de ciertas expresiones de origen arábigo «en alguna de las Repúblicas Australes de nuestro continente» $(1877,955)$. Para ello, solicita a la dirección que «se sirva publicar esta carta-pregunta en su acreditado periódico, cuya extensa circulación permite esperar que, si por este camino [no] se puede llegar a averiguar el punto, acaso vaya a dar esta pregunta con quien tenga modo de contestarla» (ídem). En este sentido, el triunfo de Esneda o Amor de madre, del colombiano Eustaquio Palacio, en el último certamen convocado por LEC para premiar «una leyenda en verso inédita i orijinal en que se respete los dogmas i la moral católica» (Anónimo 1874b, 466) evidencia que la internacionalización fue un componente clave en la estrategia de mercado adoptada por el semanario para sostener su actividad editorial. Sobre este punto, nos limitaremos a constatar la frecuente presencia en $L E C$ de autores americanos - entre los que se cuentan Jorge Isaacs (Colombia), Juana Manuela Gorriti (Argentina), Ricardo Palma (Perú) y Dolores Sucre (Ecuador) - y la temprana consolidación de redes de cooperación y canje entre el periódico santiaguino y otros medios afines a su proyecto editorial, como La Caridad, de Bogotá, perteneciente a la Sociedad San Vicente de Paul, o El Mensajero del Pueblo, vinculado con el Club Católico de Montevideo. Esta estrategia de cooperación interamericana permitía solucionar, por lo menos en parte, la dependencia crónica de unos «colaboradores obligados que nunca colaboran» (Anónimo 1872, 450), dependencia que sin duda contribuyó al cierre prematuro de la mayoría de las revistas culturales y literarias del Chile decimonono.

Por otra parte, es necesario destacar que uno de los factores centrales que afectaban la consolidación de una prensa literaria en el país era, a juicio de los editores de $L E C$, el escaso reconocimiento otorgado a la literatura como labor productiva, lo que en la práctica implicaba condenar a los escritores a una baja o nula remuneración: «Chile - afirmaban- es el único país donde todos los que trabajan en un periódico literario [tienen] que trabajar gratuitamente. La prensa política paga sus redactores, sus corresponsales, cronistas, editores, etc.; la prensa literaria a nadie paga: llena de favor sus columnas» (ídem). Esto suponía un freno al potencial crecimiento del mercado literario en términos de oferta de contenidos, situación que buscaron remediar parcialmente gracias a los certámenes literarios examinados en el apartado anterior. Integrar activamente al público lector en la cadena productiva fue otro mecanismo empleado, lo que se verificó, por ejemplo, a través de la publicación de volúmenes especiales como parte de la llamada Biblioteca de La Estrella de Chile, donde se recopilarían artículos de alta demanda, como sucedió con «una copiosa edición por separado de los artículos que con el título [de Los jesuitas $i$ sus detractores] ha venido publicando en estas columnas nuestro inteligente e ilustrado colaborador don Máximo R. Lira [...] accediendo a la petición de algunos suscritores de La Estrella de Chile» (Anónimo 1870e). Otro modo de integrar al público de $L E C$ fue a través de la colaboración directa en la producción de material de lectura, que en ocasiones incluyó la adaptación de obras extranjeras, como ilustran los editores de la publicación cuando invitan a leer «con gusto el siguiente artículo que ha tenido la bondad de estractar i traducir de una revista belga una de nuestras más amables suscritoras i que versa sobre la vida de santa Cecilia» (Anónimo 1871d).

Los ejemplos señalados pueden entenderse como formas concretas de responder el llamado a «apoyar a la prensa católica i de negar todo jénero de ausilio a los diarios impíos» (R.B. 1867, 113), ya no solo entendiendo este apoyo en su significación estrictamente pecuniaria. En este sentido, a través de la suscripción, LEC ofreció a su selecto público lector - «la mui culta i distinguida sociedad de nuestro país i especialmente de esta capital» $(1868,2)$ - la oportunidad de participar en la defensa de su fe uniéndose a una cruzada moderna por la libertad religiosa y el progreso moral de la sociedad, asegurando de este modo el sostenimiento económico de este medio y de sus colaboradores más destacados - la cara positiva del llamado a negar todo tipo de auxilio a la prensa irreligiosa-, y contribuyendo de paso a su sostenimiento textual con el ejercicio de su propia escritura, desde la segura, instructiva e incluso placentera situación del lector «literario».

\section{CONSIDERACIONES FINALES}

Inserta en un periodo de transformaciones profundas, La Estrella de Chile asumió el riesgo de incidir en el curso de la historia desde un campo hasta ese momento inexplorado por la prensa católica: el campo de las producciones culturales y, especialmente, el de las artes literarias. Compartió, de esta forma, el itinerario mediador que caracterizó a las revistas de su tipo durante la segunda mitad del siglo XIX, ofreciendo acceso a una serie de géneros que, sin sacrificar el placer derivado de su lectura variada y breve, configuró un espacio de legitimidad lectora para los nuevos sujetos alfabetizados. Sin duda, su apuesta siguió la orientación general que dominó la labor de la prensa confesional de su momento: la defensa de la Iglesia en una realidad cada vez más secular o, si lo queremos expresar en otros términos, la conservación de los distintos elementos que configuraban el estático orden de la tradición en un mundo dinámico y relativo, definido por las móviles coordenadas de su modernización; sin embargo, situada en el incierto terreno de la praxis poética, $L E C$ se hizo cargo de esta tarea con una mirada atenta a lo que constituía el devenir literario de su momento histórico, sin dejar de censurarlo, como correspondía a su estricta base doctrinaria, pero dejándose atrapar, en ocasiones, por su seductora influencia.

La perspectiva nacional con la que los editores de $L E C$ intentaron dirigir la actividad de sus colaboradores legó a la historia de la literatura chilena probablemente las mejores páginas de su propuesta, aunque esto haya significado, en la práctica, desafiar los lineamientos sugeridos por las voces más autorizadas dentro de la revista. En efecto, ignorando en parte la normativa del maestro Rodríguez y atemperados por su visión cristiana del mundo, la obra de un grupo de jóvenes escritores católicos intentó situarse en un espacio narrativo conciliador, apelando al otro indígena desde una mirada sin duda lastrada por los prejuicios raciales propios de su época, pero abierta al diálogo que el ideal católico 
y cristiano ya había inaugurado desde tiempos coloniales. El punto culminante de este proceso sería el proyecto histórico-narrativo de Enrique del Solar, quien a partir de sus tradiciones y leyendas conforma un relato nacional a partir de tramas narrativas que situaron invariablemente la barbarie anidando en el corazón de los dueños del poder político, económico y sexual de sus relatos - el hombre blanco- en un giro que, nos parece, se articula con el programa doctrinario expuesto por el semanario en su lucha por contener el avance de una civilización secular cuya única medida fuese el hombre y sus ciegas pasiones, ciclo narrativo que por su interés merece un estudio particular.

En síntesis, conservadora del orden social legado por la colonia, pero al mismo tiempo defensora de la libertades públicas conquistadas tras las guerras de Independencia; situada a medio camino entre una herencia moral que orientaba su actividad y una modernidad que amenazaba sus valores pero que al mismo tiempo posibilitaba su existencia en tanto que empresa periodística y validaba su misión como proyecto cultural, la historia de $L E C$ narra el devenir de un medio que apostó por jugar un rol en la selección de un pasado y su conexión en el presente, es decir, en la invención de una tradición cultural para un Chile en tránsito, a medio camino entre lo irremediablemente perdido y lo perplejamente por-venir.

\section{FUENTES}

Anónimo. 1867. «Prospecto». La Estrella de Chile 1, 6 de octubre: 1.

Anónimo. 1868. «Lo que hemos hecho i lo que esperamos hacer». La Estrella de Chile 54, 11 de octubre: 1-3

Anónimo. 1870a. "Círculo de colaboradores de La Estrella de Chile». La Estrella de Chile 136, 8 de mayo: 483-484.

Anónimo. 1870b. «Certamen literario». La Estrella de Chile 137, 15 de mayo: 514.

Anónimo. 1870c. «Nuevo certamen literario». La Estrella de Chile 151, 21 de agosto: 723 .

Anónimo. 1870d. «Cuarto Año». La Estrella de Chile 158, 9 de octubre: 1-2.

Anónimo. 1870e. «Biblioteca de la Estrella de Chile. Los jesuitas i sus detractores». La Estrella de Chile 166, 4 de diciembre: 144.

Anónimo. 1871a. "Periódicos literarios colombianos». La Estrella de Chile 182, 26 de marzo: 407.

Anónimo. 1871b. «Certamen». La Estrella de Chile 185, 16 de abril: 460.

Anónimo. 1871c. "Aviso». La Estrella de Chile 388, 11 de octubre: 508.

Anónimo. 1871d. «Santa Cecilia. Su influencia sobre la literatura i las bellas artes». La Estrella de Chile 216, 19 de noviembre: 99.

Anónimo. 1872. «Un nuevo colega i la fraternidad literaria». La Estrella de Chile 238, 21 de abril: 449-451.

Anónimo. 1873a. «Séptimo año». La Estrella de Chile 314, 12 de octubre: $1-2$.

Anónimo. 1873b. «Certámenes literarios». La Estrella de Chile 314, 12 de octubre: 3-4.

Anónimo. 1874a. «Mejoras en nuestro periódico». La Estrella de Chile 366, 11 de octubre: 3-4.

Anónimo. 1874b. «Nuevo certamen literario». La Estrella de Chile 343, 3 de mayo: 465-466.

Briseño, S. 1867. «La imprenta». La Estrella de Chile 2, 13 de octubre: 14.

Blanco, V. 1872. «¿Se lee o no se lee?». La Estrella de Chile 240, 5 de mayo: 485-487.

CNCA. 2015. Plan nacional de la lectura 2015-2020. Disponible en: <https://www.cultura.gob.cl/wp-content/uploads/2011/08/plannacional-lectura.pdf $>$ Consulta 21-01-2019
Cuervo, J. 1877. «Carta a la redacción». La Estrella de Chile 519, 16 de septiembre: 954-955.

Cousin, Victor. 1873. De lo verdadero, lo bueno y lo bello. Curso de filosofía sobre el fundamento de dichas ideas absolutas. Valencia: Librería de Pascual Aguilar.

Del Solar, E. 1867. «La reacción». La Estrella de Chile 12, 22 de diciembre: 133-134.

Felix, C. 1866. Conferencias del Rdo. P. Félix, en la Santa Iglesia Metropolitana de Nuestra Señora de Paris, durante la Cuaresma del año de 1866. Madrid: Imprenta de la Esperanza.

Gumucio, R. 1877. "La Estrella de Chile». En Un libro más. Colección de artículos, R. Gumucio, 76-98. Santiago de Chile: Imprenta de "La Estrella de Chile».

R.B. 1867. «Necesidad de protejer a la prensa católica i obligación de negar todo jénero de auxilios a la prensa irrelijiosa». La Estrella de Chile 10, 8 de diciembre: 111-113.

Rodríguez, Z. 1870a. «La novela i sus escollos». La Estrella de Chile 152, 28 de agosto: 739-744.

Rodríguez, Z. 1870b. «La novela i sus escollos». (Conclusión). La Estrella de Chile 153, 4 de septiembre: 755-760.

Rodríguez, Z. 1871a. «Nuestro ideal literario». La Estrella de Chile 211, 15 de octubre: 17-20.

Rodríguez, Z. 1871b. «Nuestro ideal literario». (Conclusión). La Estrella de Chile 212, 22 de octubre: 33-37.

Sánchez, A. 1873. «Los novelistas i la novela». La Estrella de Chile 318 , 9 de noviembre: 73-76.

\section{BiBLIOGRAFÍA}

Bernedo, Patricio. 2006. «Prensa e Iglesia en el chile del siglo XIX. Usando las armas del adversario». Cuadernos de Información 19: 102-108.

Barraza, Eduardo. 2013. Adelantados y escritura de la conquista. Imaginarios historiográficos en la literatura chilena. Santiago de Chile: Editorial USACH.

Castillo, Claudia. 2008. "La fe en hojas "de a centavo". Prensa católica en Chile, sus lectores y el caso de El mensajero del Pueblo, 18701876». Teología y vida XLIX: 837-874.

Cherniavsky, Carolina. 2015. La religión en letra de molde. Iglesia y prácticas de lectura en la Arquidiócesis de Santiago 1843 - 1899. Santiago de Chile: Ediciones Universidad Católica de Chile.

Cid, Gabriel. 2012. «La Revista Católica: prensa, esfera pública y secularización en Chile (1843-1874)». Mapocho 71: 137-155.

Cornejo, Marina. 2015. Revistas culturales chilenas del siglo XIX (18421894): historia de un proceso discontinuo. Santiago de Chile: Ediciones UCSH.

Correa, Sofía. 1997. «Zorobabel Rodríguez, católico liberal». Estudios Públicos 66: 387-426.

García, Francisco. 2004. «Abdón Cifuentes, un publicista católico frente al Estado liberal. Chile, 1862-1890». Historia y memoria 8: 297-338.

Láscar, Amado. 2005a. «Blest Gana y el límite de lo indígena en la integración al Estado-nación chileno». En Mariluán, Un drama en el campo, ed. Alberto Blest Gana, 118-144. Santiago de Chile: LOM Ediciones.

Láscar, Amado. 2005b. «Consolidación del estado-nación y las contradicciones de la perspectiva indianista: Gualda, Cailloma y A orillas del Bío-Bío». Alpha 21: 63-86.

León, Marco. 2011. «Una gradual secularización de lo cotidiano. Espacios, memorias y rituales mortuorios en Chile (1850-1930)». En: Historia de la iglesia en Chile. Tomo III. Los nuevos caminos: Ia Iglesia y el Estado, ed. Marco León, 482-536. Santiago de Chile: Editorial Universitaria.

Muñoz, Javier. 2012. "La imagen del liberalismo desde el diario El Estandarte Católico durante el gobierno de Aníbal Pinto Garmendia (1876 -1881)». Universum 27: 113-142. 
Ossandón, Carlos. 1998. El crepúsculo de los sabios y la irrupción de los publicistas. Prensa y espacio público en Chile (siglo XIX). Santiago de Chile: LOM Ediciones.

Poblete, Juan. 2002. Literatura chilena del siglo XIX: entre públicos lectores y figuras autoriales. Santiago de Chile: Editorial Cuarto Propio.

Subercaseaux, Bernardo. 2002. Nación y cultura en América Latina. Diversidad y globalización. Santiago de Chile: LOM ediciones.
Santa Cruz, Eduardo. 2010. La prensa chilena en el siglo XIX. Patricios, letrados, burgueses y plebeyos. Santiago de Chile: Editorial Universitaria.

Stuven, Ana María. 2009. "“Cuestión social” y catolicismo social: de la nación oligárquica a la nación democrática». En Catolicismo social chileno: Desarrollo, crisis y actualidad, ed. Fernando Berríos y Jorge Costadoat 36-63. Santiago de Chile: Ediciones Universidad Alberto Hurtado. 